\title{
Cash Burning Machine: Uber's Logic of Planetary Expansion
}

\author{
Luke Munn
} Western Sydney University, Tāmaki Makaurau Auckland, Aotearoa New Zealand,
lukemunn@lukemunn.com, lukemunn.com

\begin{abstract}
Uber's programme of planetary expansion rapidly captures users and integrates cities. Like other platforms, Uber privileges growth at all costs in order to spin up a set of selfreinforcing dynamics like virtuous cycles and network effects. However, drawing on Arrighi, Hobson, and Arendt, Uber can also be understood as a contemporary incarnation of imperialism. Platforms extend their territories in a programme of aggressive expansion rationalized by future financial gains. The article combines these self-perpetuating technical dynamics with the self-expanding logics of empire. Against the assumed brilliance of founders and the strategic innovation of start-ups, this framing highlights some of the uncontrolled forces and overarching imperatives that both invest and constrain platforms.
\end{abstract}

Keywords: Uber, platforms, network effects, expansion, territory, imperialism

\section{Introduction}

For years Uber's financials were a closely-guarded secret. However, in 2017, Uber lifted the veil, disclosing the four quarters of figures to Bloomberg. The results are staggering, if not entirely unexpected. Since its founding in 2009, Uber has burned through at least $\$ 8$ billion. In one recent quarter the company lost $\$ 980$ million (Newcomer 2017). By comparison, Amazon.com, the poster child of the longunprofitable technological corporation, never lost more than $\$ 2$ billion in a year, and that in the wake of the dot-com bubble (Newcomer 2017). These losses are historically unprecedented. They certainly defy the fundamental (albeit simplistic) logic of basic entrepreneurialism. Yet investors are reportedly undaunted, aware that Uber is using Amazon as the blueprint for market domination (Fiegerman 2017). If the FANG companies (Facebook, Amazon, Netflix, and Google) establish a new operational logic, it is one that doesn't register as a conventional success on a profit and loss sheet. Indeed, a rivalry seems to emerge between the economic and the technical based on a fundamental "difference in their desires" (Jünger 1990, 32). When asked by Bloomberg (Newcomer 2017) to sum up Uber's financials, finance professor Aswath Damodaran simply said, "this is a cash-burning machine".

What is the logic of this cash burning machine? This article investigates the imperative of growth embraced by Uber. If Uber is certainly a company, this analysis will stress it as a platform. Despite its frequent everyday use, 'platform' is an ambiguous term, with divergent meanings sourced from computational, architectural, figurative, and political spheres (Gillespie 2010). Dal Yong Jin $(2017,37)$ suggests three core aspects of a platform: (1) a platform is not only hardware architecture but a software framework, (2) platforms mediate relations, providing opportunities to communicate, relate or sell, and (3) platforms are designed in particular ways, contributing to a political culture. From an economic perspective, platforms are often understood as being two-sided markets that interface between two parties such as buyers and sellers (Codagnone, Matthews and Karatzogianni 2018). Bringing these definitions together, 
a platform here is understood as an extendable computational architecture that facilitates value-generating interactions.

Platforms offer new functionality and thus prioritise a new objective. Core to this article's analysis is that the technical architectures of contemporary platforms offer a novel set of affordances, allowing them to scale rapidly and inexpensively with "growth models not readily found in mainstream business" (Anwar 2018, 66). The key research question investigated is therefore: what are the new sets of dynamics and imperatives initiated by the platform model? Sections 2 and 3 of this article explain how Silicon Valley platforms like Uber have drawn on concepts like aggregating users, virtuous cycles and network effects to form a logic of aggressive expansion that is intensely pursued. In this 'winner takes all' mentality, scale subsumes strictly financial value and platforms expand rapidly, capturing consumers and aggregating suppliers. Uber is the paradigmatic example of the global expansion enabled by platforms, and academic literature abounds with glowing articles on its rapid rise (Bond 2015; Watanabe et al. 2017; Dudley et al. 2017).

However, in Section 4, Uber is slotted into an imperial lineage to suggest a darker picture of platform capitalism. Drawing on the work of Arrighi, Hobson and Arendt, Uber's global growth is reframed as a programme of annexing territory to leverage for financial accumulation. Section 5 combines these self-expanding imperial drives with the self-perpetuating technical cycles discussed earlier to form an image of Uber that is both more compelled and more uncontrolled. All-encompassing growth takes on a life of its own. Against the assumed brilliance of the start-up and its founder, expansion becomes an impersonal and unsubordinated process.

\section{Aggregating at Scale}

Uber epitomises one of the core promises of platform capitalism - functionality at scale. To understand how its technical architecture establishes a company-wide imperative of growth, this section draws upon the concept of aggregation developed by technology analyst Ben Thompson. Thompson is not an academic, and in many respects is drawing on established concepts in business studies: transaction costs (Coase 1937), vertical integration (Grossman and Hart 1986), network effects (Rochet and Tirole 2003), and virtuous cycles (Casadesus-Masanell and Ricart 2011). Thompson's contribution, then, is essentially a synthesised model for explaining the power of platforms. However, Thompson is used here specifically because his analyses are highly influential within Silicon Valley. His concept of aggregation has been taken up by those at Google (Anazodo 2016) and Microsoft (Griffin 2017), his subscribers include the CEOs of Linkedln and DropBox, and his concepts are internalised by many in the start-up sector. ${ }^{1}$ In other words, this is how platforms themselves understand their model and the imperative to scale.

Thompson (2015) begins with the simple proposition: "The value chain for any given consumer market is divided into three parts: suppliers, distributors, and consumers/users". One of the primary ways to generate profits used to be the integration of supply and distribution components. Take newspapers, for example. Before the advent

1 "About three years ago, Thompson, then an unknown former analyst at Apple and Microsoft, founded his tech blog stratechery.com to little fanfare. Today, his subscription model nets him $\$ 200 \mathrm{~K}$ in annual revenue. His in-depth analysis [sic] are read by CEOs and VCs from around the world. His subscribers include the top of the top in the tech scene, such as Jonah Peretti (CEO Buzzfeed), Jeff Weiner (CEO Linkedin) and Drew Houston (CEO Dropbox)". OMR Festival (2016). 
of the Internet, distribution was a difficult problem. For an advertiser to reach an individual at their home would require a door-to-door campaign, a highly expensive and highly localised endeavour. Through a complex and costly infrastructure of printing presses, trucks, paperboys, and so on, newspapers solved this distribution problem, albeit for a fixed geographical region. Next, they integrated distribution with supply, bringing together reporters, writers, journalists - often under a single roof - to produce content. This allowed advertisers to deliver their messages literally to the front doorstep of every home, and resulted in a century of lucrative profits for the major papers. As Thompson (2015) explains, taxis followed the same model, integrating dispatch (distribution) together with a fleet of cars and drivers (supply). In a similar fashion, hotels integrated a trusted nationwide brand (distribution) together with an infrastructure of empty rooms (supply). For consumers, these integrations produced a reliable and profitable package, but also a highly generic one (think again of the newspaper or the newsreel). Users got what they got.

The Internet fundamentally changes this dynamic. Distribution, at least of digital goods, is no longer a difficult problem. Indeed, overlooking for a moment the fixed capital of infrastructure networks, it can essentially be done for free. As Thompson (2015) observes, this reconfigures the competitive terrain, "neutralizing the advantage that pre-Internet distributors leveraged to integrate with suppliers". This allows companies to establish a one-to-one relationship with individual users. The business focus swings in the opposite direction, from supplier to consumer. Companies no longer compete for exclusive supplier relationships; instead "suppliers can be aggregated at scale leaving consumers/users as a first order priority" (Thompson 2015).

Given these conditions, the user experience now becomes critical and companies must effectively fine-tune the parameters which constitute it. To be sure, these encompass anxieties around obvious user-facing components. Uber, for example, has redesigned both its own brand identity and its web and mobile interfaces multiple times since launching in 2009. ${ }^{2}$ Yet even supplier issues get recast as parameters that can make or break the consumer experience. In 2014, for example, Uber added a Safe Rides fee in an attempt to reassure their users with "an industry-leading background check process, regular motor vehicle checks, driver safety education, development of safety features in the app, and more" (RideGuru 2016). To draw users in, to provide them with value, to respond to their needs - these are the new imperatives.

If hurdles like these can be overcome and a consistently satisfying experience achieved, then a 'virtuous cycle' is instigated: the best experience wins users, more users attract more suppliers, and more suppliers improve the experience by providing more content, more choices, closer proximity, and so on (Thompson 2015). In the schema of aggregation theory, companies attempt to trigger this self-reinforcing mechanism, to set it in cyclical motion. If successful, their initial work begins to work for them. "Getting this spiral kick-started is one of the challenges to any new entrant seeking to gain entrance", explains Tom Slee $(2017,130)$ : "The technology component of the business is amortized over all the cities in which Uber operates, so its success in New York helps its business in San Diego". By turning towards customers and obsessing over their experiences, companies strive to trigger a feedback spiral that builds organically into a better product.

${ }^{2}$ Based upon the author's design analysis of Uber branding and interface elements as they evolved since the company's founding. 
Just as importantly, this user relationship can be established at scale. Traditionally for companies the addition of every new customer incurred a transaction cost. Thompson (2017) gives the example of a cellular network company; to bring a new consumer on board entailed talking with them on phone or in person, collecting their details, running a credit check, furnishing them with a SIM card and telephone, managing renewals and upgrades, and so on. Adding each new customer undoubtedly brought profits. But it also required expenditure, not only in the initial 'onboarding', but in the financial investment required to service this expanded customer base: more infrastructure to maintain a quality service, more labour to staff customer support centres, more complexity due to expanded markets or diversified product lines, and so on. At some point the cumulative effect of these transaction costs begins to impinge too heavily on the profits to be gained (see Langlois 2006). In contrast, one of the unique qualities of the new breed of companies like Google, Airbnb, and Uber is that their transaction costs are zero. For corporations such as these, Thompson (2017) asserts, "adding one more customer is as simple as adding one more row in a database". An array of automated mechanisms allow the user to register, to set up payment options, to maintain their account, to customise their service, and even to receive their product. With zero transaction costs, these companies have every incentive to scale.

Scale becomes critical. As Thompson (2017) points out, the "value of the service increases as the number of customers increases". As discussed, the aggregator that holds the most users also holds the most attraction for suppliers - drivers go where the passengers are, marketers spend where the eyeballs are, landlords list where the tourists are. How much value does every customer add? For a quantitative solution, Thompson refers to Robert Metcalfe, inventor of the Ethernet protocol. In a 1980 sales slide, Metcalfe (2007) posited a law stating that the "value of a telecommunications network is proportional to the square of the number of connected users of the system (n2)"3. At that time, Metcalfe was actually referring to devices - fax machines, printers, servers, and so on. Two telephones can only form a single connection, whereas 12 telephones can form 66 connections. Yet the law has also proved prescient for human connections in the age of Web 2.0.

While some critics assert that the law overestimates the values of networks, Metcalfe (2013) himself has recently applied it to Facebook, demonstrating that the financial worth of the social network closely approximates the Law. Facebook is a unique case in that its users are also suppliers - content creators who post selfies, status updates, and everyday activity for free. As Facebook establishes its privileged relationship with an ever-broader population, it approaches the status of social monopoly, exerting a stronger pull on both advertisers and individuals. Indeed, as computer scientists Zhang et al. (2015) recently demonstrated with both Facebook and Tencent, it is not just the value of these social networks that match Metcalfe's law, but their growth trends. With each new user adding an amplified degree of value, the primary goal becomes exponential growth. Here, value does not just become conflated with scale, but subsumed by it.

In the logic of expansion, the winner takes all. To be sure, the addition of each user improves that particular service - elevating the overall level of demand, the overall diversity, the amount of content available, the quantity of information captured, and so on. But services do not exist in a vacuum. The relentless drive to encapsulate more

${ }^{3}$ Like many other computer science concepts, Metcalfe's law was introduced informally and grew slowly in recognition. Metcalfe mentioned it on a $35 \mathrm{~mm}$ slide when he was selling Ethernet to clients in 1980. In 1993, George Gder, an influential tech analyst, resurrected it, named it after Metcalfe and formalised it (Metcalfe 2007). 
users takes place on highly contested terrain. Theoretically, of course, consumers and suppliers can participate in multiple platforms or products. In practice, platforms strive to establish exclusivity. As Thompson (2014) explains, for consumers this often entails brand allegiance - in an undifferentiated market (e.g. Lyft vs Uber), constant comparisons aren't worth the time and effort, users choose a company and stick with it; for suppliers, investment is a zero sum game - every minute or dollar given to one company (e.g. Uber) is one not going to a competitor (e.g. Lyft). Veteran driver and rideshare blogger Harry Campbell confirms this (Bogage 2016), stating that the required acceptance rates for drivers effectively mean that "they're basically requiring you to only work for Uber".

Recognising the stakes, companies often sharpen rather than soften these fundamental antagonisms. Uber CEO Travis Kalanick famously stated they were competing against the "asshole" called taxi, and the company has run billboard campaigns like "Shave that Stache" trying to coerce drivers to move away from Lyft and its iconic moustache (Gannes 2014). Shortly after, Uber upped the ante further. As The Verge reported (Newton 2014), the company organised off-the-clock "slogging" street teams with high commission rates to aggressively recruit Lyft riders, arming them with signup sheets and second iPhones in case they got caught.

On the consumer side, these companies also employ a bevy of techniques designed precisely to achieve maximum lock-in (Amarsy 2015). The best user experience is attained by remaining within each proprietary ecosystem, or 'walled garden'. As Bruce Berls (2018) explains, "each company hopes to keep you within its garden by making its services and devices work better if you stay in its embrace". Previous history functionality is one such mechanism - the more one uses the service, the more data it has; more data means better prediction and more value. Once understood, this feedback loop of activity-based anticipation appears across many platforms: music (Spotify), movies (Netflix), shopping (Amazon), search (Google) and others. Switch to a competitor, and you start with a fresh slate, a condition in the tech world that is not refreshing so much as frustrating.

Whether recruiting, enticing or locking in, regardless of the techniques employed, the logic of expansion is the same - to capture every user, and in so doing, to strongarm every supplier. "Since platforms are grounded upon the extraction of data and the generation of network effects", explains Nick Srnicek $(2017,126)$, "certain tendencies emerge from the competitive dynamics of these large platforms: expansion of extraction, positioning as a gatekeeper, convergence of markets, and enclosure of ecosystems". In the broader, brutish environment of capital, flatlined equilibrium is not an option. A service is either growing, increasing its user-base and crushing its competitors, or it is shrinking. As tech analyst Abhishek Madhavan (2017) stresses, "that's the thing about network effects - they work against you until you reach a tipping point; then, they work for you. And often to devastating effect for the competition".

\section{Accumulating Users, Swallowing Cities}

In the logic of expansion, the race to this tipping point trumps all else, capital included. To rationalise this logic, a reconfiguration of parameters is needed, a shift not only from short-term to long-term, from profits to losses, but also from financial value to human value - from money to monthly-active-users (MAUs). Monthly active users, as the term suggests, is simply a metric of the number of users that regularly sign into and use a service, as opposed to dormant accounts. For years, Uber was not a publicly-listed company, and thus not required to disclose this kind of information, making any detailed analysis difficult. But there were two known data. In December 2013 a 
document was leaked showing the number of rides requested, week by week, over October and November. Prosperity Analytics simply averaged these figures to arrive at a very defensible figure of 1,055,842 - just over a million MAUs (2014). Just three years later, in October of 2016, CEO Travis Kalanick revealed at the New Establishment Summit that Uber had 40 million MAUs (Lynley 2016). Using a highly simplistic linear growth rate between these two points, this entails adding almost 37,000 new users per day, or just over 1.1 million MAUs per month. Filling in the blank time with a more realistic growth factor of $180 \%$ links up the two known data, resulting in a Metcalfian curve (Figure 1). This is staggering growth, but measured in users, not revenue.

Very recently in May 2019, Uber filed for its initial public offering on the stock exchange, a move that required the company to reveal much more internal data about its operations. Uber's SEC-1 filing document claims it now has 91 million "monthly active platform customers"; however, this figure combines Ridesharing, New Mobility and UberEats users, resulting in a large but rather vague number (Uber Technologies Inc 2019, 101). While there is a huge amount of information to digest in the 300 pages of this document, the imperative to growth and the privileging of scale over profits can again be witnessed. Core platform margin has recently dipped to -3\% in Q4 of 2018, and yet the company wants to reassure shareholders, believing that it "can continue growing" its user base given that it still only represents " $2 \%$ of the total population in the 63 countries in which we operate" (Uber Technologies Inc. 2019, 101).

\section{Uber Monthly Active Users}

50

40

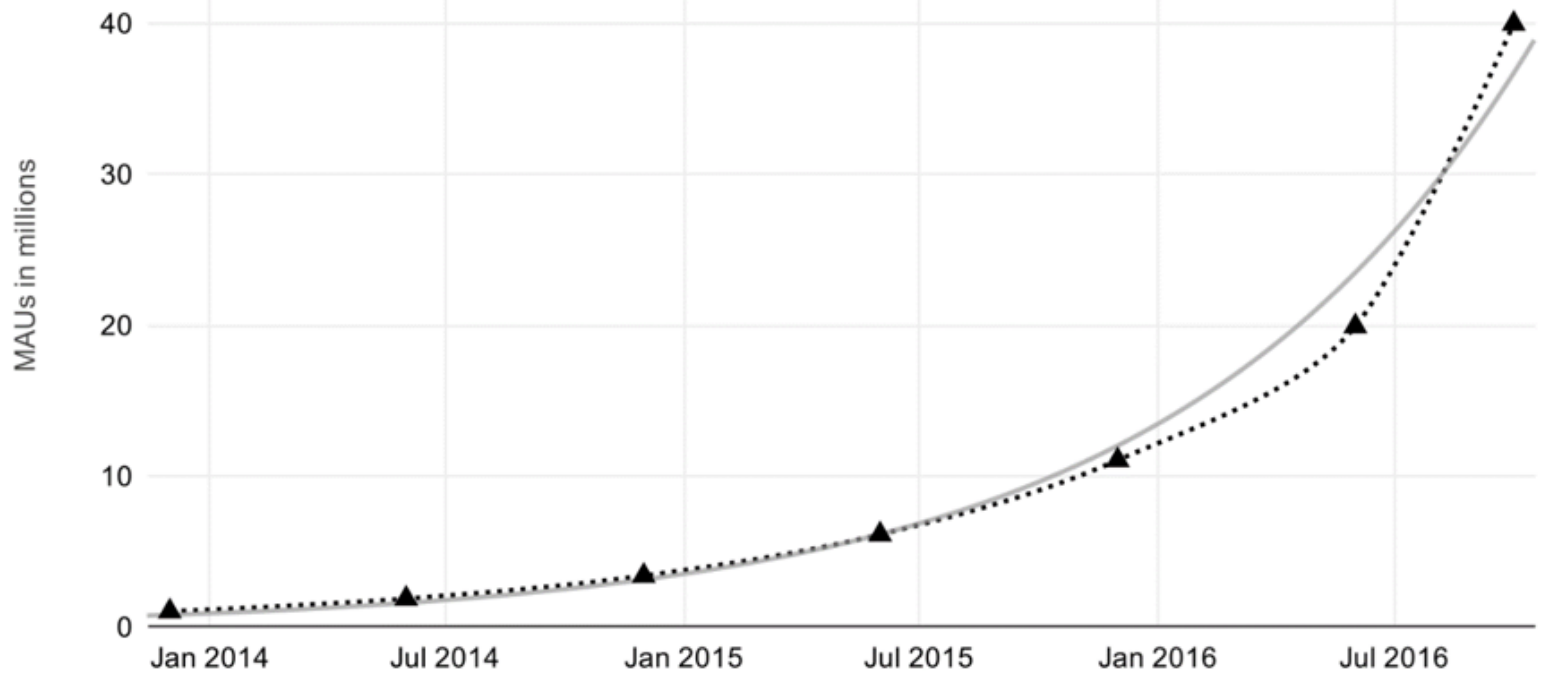

Figure 1: Uber Monthly Active Users, linking 2 known data with estimated growth rate

To enlist a new pool of drivers and to thereby entice a new user-base of riders is a highly expensive bootstrapping operation. Given this strange new logic, it makes sense to subsidise the cost of each ride by $50 \%$ or more, particularly when entering a new market (Kaminska 2016). This means that steadily skyrocketing user growth occurs simultaneously with heavy financial losses from quarter to quarter. This is the logic that underpins Uber as a success story while simultaneously inspiring headlines such as "Why Uber Is Losing Money Faster Than Any Tech Company Ever" (Nunez 2016). 
The Uber machine thus burns cash to accumulate (human) capital. Of course, the maximum user-base is not confined to a particular city or country, but spread across a broad geography of countries and territories. Again, scaling becomes critical. The endpoint of any expansion must be global in scope - the objective is an exhaustive capture of the totality. The "cash-burning" machine has certainly followed this trajectory. In 2010 Uber began in San Francisco. In 2011, it had already expanded to six cities, including its first international launch in Paris. In 2012, it doubled that to twelve cities. In 2013, it added 47 new cities. By 2014, it was launching in a new city every 2 days, totalling 240 cities in 46 countries (Milian 2014). By 2019, according to Uber's website, the ride-sharing service was available in over 700 cities worldwide.

To understand this growth more specifically, I compiled a city launch timeline for Uber. When launching in a new city, Uber releases a boiler-plate welcome post on its blog. By documenting the time and city from each of these posts, a basic logic of expansion emerges. Uber begins slowly, spreading to major Western hubs such as NYC and London, but then slowly builds inertia, encroaching into midsize centres in Europe, before accelerating in its growth rapidly by spreading to hundreds of smaller towns worldwide. Since compiling this timeline, Uber has sought to match Lyft's regional focus by annexing ever smaller suburbs in the USA (Ryan 2017). At the same time, it has been attempting to penetrate into the Latin America market, where its quasiillegal status often means it has to operate covertly (Moed 2018).

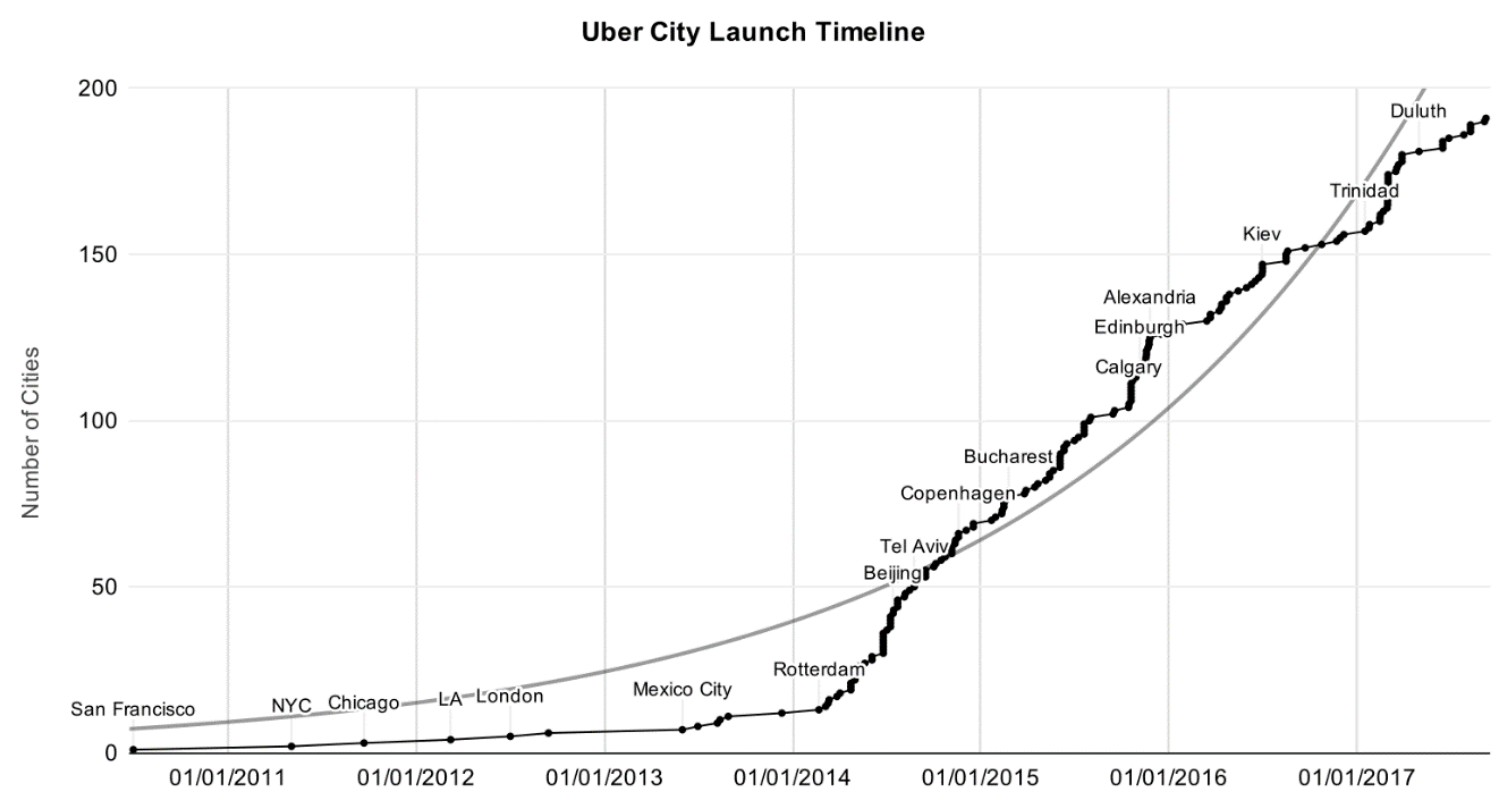

Figure 2: City Launch Timeline based on data collected from Uber blog posts by author

\section{Converting Territory to Capital}

What is the end-game for all of this growth? One of the ways to understand this aggressive programme of global capture is through Giovanni Arrighi's notion of territorial expansion. In The Long Twentieth Century, the economist and world-systems analyst argued that empires throughout history have been characterised by two distinct modes: the capitalist and the territorial. When the capitalist mode dominated, the accumulation of wealth was the primary driver. When the territorial mode was 
privileged, the dictates of capitalism by no means disappeared, but the colonisation of new spaces became the priority. In this second mode, money was merely "a means or intermediate link in a process aimed at the acquisition of additional territories" (Arrighi $2010,111)$. Arrighi thus transforms Marx's famous circuit of M-C-M' - in which money $(\mathrm{M})$ is exchanged for commodities $(\mathrm{C})$ that are then sold for more money (M') - into $\mathrm{M}$ T-M', whereby money drives the expansion of territory, which through land holdings, colonial labour, financial levies, and so on, is leveraged towards increased wealth (Arrighi 2010, 111).

From the British to the Genoese, Arrighi chronicles the long history of national empires oscillating between these two modes. Slotting platforms into this lineage of empire building begins to counter their ahistorical framing as revolutionary and disruptive. Such "technological fetishism" and its "fascination with the new" masks the digital labour inherent within platforms, labour that can be understood through the concept of imperialism (Fuchs 2016). Platform imperialism has been developed at length by Dal Yong Jin, who defines it as "an asymmetrical relationship of interdependence in platform technologies and political culture between the West, primarily the U.S., and many developing countries" $(2017,42)$. However, while Jin sees platform imperialism as a key extension of Western power, the emphasis here is on platforms as empires in themselves. Arrighi's description of the Dutch empire in the 18th century as "high value-added industries" in the capital, underpinned by "the creation of a world-wide network of commercial outposts and exchanges" $(2010,617)$ could equally be applied to Uber.

The logic of growth stressed by such platform empires resonates with what Arrighi refers to as a "purely commercial or mercantile logic of expansion - a logic in which the expansion of trade is an end in itself so that profits are routinely reinvested in it" $(2010,638)$. Of course, Uber will not expand forever. Rather than a "cash burning" machine, the shareholder dream is that it will become something akin to a "cash printing" machine, a sustainably profitable company delivering high returns on investment. There is a secondary logic at work here that drives expansion into new cities and new territories. After all, as Arrighi $(2010,640)$ noted: "An agency that reinvests routinely the profits of trade in the further expansion of trade as long as the returns to the capital so invested are positive cannot be defined as 'capitalist' by any stretch of the imagination". Mercantile expansion is not an end in itself.

Instead, Uber's vision is that the monopolisation of territory, and the riders and drivers associated with it, becomes the basis for lucrative new forms of financialisation. In The Geometry of Imperialism, Arrighi frames this drive as a vector, "the tendency of high finance to press for territorial expansion [...] as a way of opening up new areas of financial intermediation" $(1978,118)$. Indeed, finance provides expansion with an overarching goal. Arrighi's book dialogues at length with John A. Hobson's study of imperialism. "The motor-power of Imperialism is not chiefly financial", stresses Hobson, $(1902,50)$ "finance is rather the governor of the imperial engine, directing the energy and determining its work: it does not constitute the fuel of the engine, nor does it directly generate the power". Expansion needs to be guided, steered towards particular paths. Expansion, "though strong and genuine, is irregular and blind", asserts Hobson (1902, $50)$, "the financial interest has those qualities of concentration and clear-sighted calculation which are needed to set Imperialism to work". The logic of territory is guided by the logic of capital.

Platforms certainly offer many paths to capitalization: commission fees, advertising revenue, selling personal data, service charges, business-to-business collaborations, and others (Muzellec et al. 2015). Indeed, as Anne Helmond suggests (2015), the 
"modular technical architecture" of platforms "connects to their economic model". In other words, the extendable nature of platforms allows new profit-making avenues to be experimented with and then strapped on, building atop the original functionality of the platform. The meal delivery service UberEats, launched in 2014, and the logistics service UberFreight, begun in 2018, are both classic examples of this strategy.

Moreover, the inherent flexibility of a platform's technical architecture even allows existing services to be financialised in new ways. By changing a variable or tweaking some code, digitally-mediated services can be rapidly reconfigured. Uber's history of altering their commission on each ride is a clear example of this strategy. "Over time, Uber has taken a larger and larger slice of every fare", Tom Slee $(2017,136)$ explains: “In April 2014, Uber introduced a \$1 per trip safety fee, increasing the company's slice to around $30 \%$ for short trips. In July it started charging drivers $\$ 10$ per week for use of a smartphone. In September Uber increased their commission for new drivers in San Francisco to 25\% of the fare, and in May 2015 they started experimenting with taking $30 \%$ of the fare: more than most medallion owners". Whether adding new services or extracting more from existing ones, Uber draws on the inherent flexibility of platforms to rationalise its continued expansion. In the rhetoric of start-ups, the mantra is growth first, pivot to monetisation later.

\section{From Innovation to Imperialism}

Expansion, therefore, is by no means irrational. In the language of Hobson, the financial interest both demands and defends continued expansion. In the more contemporary language of start-ups, the anticipation of future dividends 'green lights' growth at all costs. The imperative of global colonisation is driven by the promise of profits to come. However, this financially-driven expansion initiates a broad and overarching set of dynamics that runs counter to the conventional framing of such companies. Here I want to start drawing together the self-perpetuating dynamics of network effects and virtuous cycles with the self-expanding dynamics of imperialism to paint a more critical image of platform capitalism.

In both academic literature and technology journalism, the global rise of platform has been lauded (Geron 2013; Sundararajan 2016; Anwar 2018). "A new breed of startups is building large empires with minimum investments", proclaims technology consultant Sangeet Choudary $(2015,1)$. Rapid and relentless, Uber's programme of expansion is the stuff of business bromides. It is Uber's "playbook" as a compilation of winning moves (Solon 2017). It is Uber's "fight" in which aggressive yet effective tactics win the day (Rothman 2016). And it is Uber's "war" where weapons and war chests allow one side to conquer their opponents (Thompson 2014). In these framings, one unique company, led by its CEO, strategically draws together brilliant tactics with brute force in order to vanquish any incumbents and dominate the global market.

Uber, as discussed, has certainly expanded rapidly. However, after its carefullyselected first round of cities, the rapid pace of expansion often renders questions of location suitability moot. As Austin Geidt, Uber's head of global expansion, said "at this point we go so quickly, I wouldn't say that it particularly matters [...] if we're not there now, we'll be there in a week" (Milian 2014). Geidt's comment begins to suggest a drive in which the specificities of somewhere largely disappear into the goal of everywhere. Cities become fungible, seen less as particular places and more as progress towards an objective. The totality is rapidly encroached upon; the next city subsumed into the total progress bar: $12 \%, 23 \%, 36 \%$. This logic resonates with the logic of imperial expansion described by Hannah Arendt (1976, 622), an "expansion which was not driven by the specific appetite for a specific country but conceived as an endless 
process in which every country would serve only as a stepping-stone for further expansion".

Platform empires do not operate in isolation. Instead, as Brett Matulis $(2016,288)$ argues, "they are agents within a framework that compels the pursuit of profit maximisation". As an agent in this framework, any company's decision-making is codetermined both by the decisions of others and the conditions common across an industry sector. Such competition means that platforms are forced to adopt the profitmaking practices of their competitors, however debilitating for workers or damaging to the earth.

Marx $(2004 / 1867,675)$ identified this phenomenon early on, stating that these laws "assert themselves as coercive laws of competition". The ethical values of an individual, the humanistic beliefs of a corporation - all these private charities must be discarded in the face of the harsh realities of the public market. Of course, this erosion of autonomy is an affront to innovation narratives and iconoclastic individuals, to the "self-determining 'genius' of the individual capitalist" (Marx 2004/1867, 742). This is why, as Marx observed $(2004 / 1867,675)$, coercion is internalised by the individual and transformed into the appearance of the self-directed, entering "into the consciousness of the individual capitalist as the motives which drive him forward". Competitive compulsion is recast as an independent course of action.

Rather than a strategy, then, the pursuit of monopolisation through expansion is a necessity. If Uber didn't undertake rapid expansion and global capture, Lyft would. If not Lyft, then Didi Chuang. If not Didi Chuang, then Gett. Indeed, Arendt's (1976, 1028) assertion that "if they do not pursue global rule as their ultimate goal, they are only too likely to lose whatever power they have already seized", while speaking of empires, could easily describe the winner-takes-all logic of platforms. While the particularities of one technique or another are left open, a platform's next move as a competitor in a global system is - if not predetermined - at least highly constrained. Platforms needed to - and have - reached scale and power, suggest Codagnone and his co-authors, avoiding existing laws, gaining wealth and political influence, and locking in consumers and workers, making it "debatable to what extent their success is attributable to pure innovation" (Codagnone, Matthews and Karatzogianni 2018, 5).

Reframing Uber and other platforms in the overarching logic of empire emphasises the broader processes that support their political economies. Such a framing contributes to platform studies, not just by countering a pro-business techno-fetishism often linked to start-ups, but by suggesting a frame of critique less distracted by detail. For example, the 'dirty tactics' of Uber have received much press: Greyball technology that blocked government regulators from receiving rides (Isaac 2017), the "canceled rides" scandal in which Uber intentionally booked and cancelled large numbers of Lyft pickups to sabotage their competitor (Fink 2014), the "God's eye view" mode that tracked an individual in real-time as a party trick (Hill 2014), and the company's suggestion to dig up personal dirt on critical female reporters (Smith 2014). Similarly the "toxic culture" of Uber has seen much spilt ink: a brogrammer culture in which data analytics determined one night stands or "rides of glory" (Harris 2012), revelations about a business evening at an escort-club in South Korea (Jones 2017), an Uber France promotion where users could win a ride with a "hot chick" (Warzel 2014), and most importantly, former engineer Susan Fowler and her explosive story of pervasive sexism and harassment (Fowler 2017a). Of course these practices should be denounced. But an imperialist framing starts to suggest that all of these specific, egodriven practices are taken up into a broader overall logic. 
The 'virtuous cycle', the 'network effect', the 'coercion of competition' - all these terms signal processes that become decoupled from the original instigators and morph into free-floating operations with their own logic and inertia. Situating these processes in the framing of imperialist expansion stresses their systemic nature. They arise not from any particular person or project, but from complex combinations of sociotechnical forces at various scales. As Schwarz $(2017,386)$ suggests, such platform logics emerge from the "specific interplay between local determinants (code-based control) and global repercussions (networked accumulation, geopolitically determined consolidation), that are simultaneously precipitating all sorts of generative, emergent, largely unforeseeable effects on a trans- or interplatform scale". Agents within these platforms are not drones - variation in approaches and innovations in technologies can certainly be witnessed. But these particularities are elided by the broader and more uncontrolled dynamics that envelop them.

Following on from this, an understanding of platforms as empires would stress operations over individuals. Propelled by network effects and compelled by an expansionist drive, the platform is governed by larger forces. Given these conditions, the activities of a leader, whether controversial or celebrated, brash or behind the scenes, become relatively inconsequential. "No matter what individual qualities or defects a man may have", writes Arendt $(1976,622)$ in Imperialism, "once he has entered the maelstrom of an unending process of expansion, he will, as it were, cease to be what he was and obey the laws of the process, identify himself with anonymous forces that he is supposed to serve in order to keep the whole process in motion". Evangelising about a new product, delivering a keynote, or conducting another interview - these highly visible actions merely tweak the parameters of a much broader process, one largely decoupled from the whims of any single figure, however "powerful" or public. The process itself moves over and above particularities and personalities.

Again, this emphasis runs counter to conventional framings. In tech and business literature, start-ups are often strongly identified with their founders or CEOs, who are seen to embody the brand and its values (Somerville and Menn 2017). Uber, for example, has long been associated with its aggressive yet 'effective' CEO, Travis Kalanick. This is a man who created the company so that he and his friends could be "ballers", who berated a driver that complained about falling fares, who penned a sex memo for a Miami celebration, and who described his ability to pick up women on demand as "boober" (Wong 2017).

These so-called 'leadership issues' dovetailed into the increasingly visible 'toxic culture' of Uber to create shareholder anxiety, resulting in the board finally forcing Kalanick to resign. He was replaced by the former CEO of Expedia, Dara Khosrowshahi, who immediately set about rewriting Uber's cultural values, literally. Khosrowshahi (2017) laid out 8 cultural norms in a public blog post: one truism affirms diversity: "We ensure people of diverse backgrounds feel welcome. We encourage different opinions and approaches to be heard, and then we come together and build"; another encompasses ethics: "We do the right thing. Period."

However, when asked to comment on these "sweeping changes" at the company, Susan Fowler - the female engineer whose explosive blog post revealed its culture of sexual harassment - dismissed the transformations as "optics" (Fowler 2017b). Of course, Fowler was referring to the announcement as a public relations move, an exercise in media management. But for Marx, rights discourse and ethical statements are often 'optical' in that they focus on the visible surface while ignoring the underlying structural dynamics. All too easily, they become empty claims rather than operating 
conditions. Indeed his analysis of capital sought precisely to move past this realm of rhetoric - "to leave this noisy sphere, where everything takes place on the surface", a sphere which was "in fact a very Eden of the innate rights of man" (Marx 2004/1867, 445).

What Marx recognised was that this paradise, which upheld human rights in theory, consistently subjugated them in the hells of industrial labour. Enshrined in law, lofty ideals were quickly discarded on the factory floor. Instead of utopian principles, he understood the efficacy of delimited struggles and practical victories - and he would gladly swap the former for the latter. As Marx $(2004 / 1867,647)$ observed: "In the place of the pompous catalogue of the 'inalienable rights of man' there steps the modest Magna Carta of the legally limited working day". The rights of workers emerge from the broader systems of production they inhabit.

In privileging growth at all costs, platforms empires establish conditions that frequently devalue such rights. These conditions establish highly precarious labour in which wages can change from one day to the next, where any slip in ratings creates high levels of anxiety in drivers, and where workers become "driver-contractors" rather than employees, stripped of safeguards like healthcare (Munn 2018). For Uber, services must be delivered consistently and professionally, but the ability of the platform to aggregate drivers means that individual workers become largely interchangeable. Service can be provided by anyone who is willing to live under such conditions. The structure of the platform economy "does not resemble a world of truly independent commodity/service producers selling directly to consumers," argues Eric Tucker $(2018,361)$, "but rather one in which workers are subordinated to platform enterprises bent on maximizing profits and expanding to become dominant players, if not monopolists, in their markets".

Understanding these broader imperatives means that Fowler's comment on the ostensible culture overhaul of Uber could be extended to a whole variety of public controversies, nasty personalities, and dubious activities - they are optical not operational. Kalanick is out, Khosrowshahi is in. Yet the technical performances that conduct geopositioning, coordinate just-in-time matching, produce surge pricing, and extract capital from workers are entirely unchanged. On a business level, this means that the aggregation of users continues, the recruitment and rating of drivers persists, and the spiralling expansion of the system is sustained. In network theorist AlbertLászló Barabási's $(2002,222)$ words, the network will keep expanding "one node at a time, taking on all the characteristics of a web without a spider". In doing so, the specificities of a 'toxic culture' and its accompanying 'leadership issues' are smoothed over, averaged into an overall vector. These particularities - pathologic as they are are subsumed into an overarching logic of imperial expansion.

\section{Conclusion}

Beginning from the seemingly paradoxical phrase of the "cash burning machine," this article has explored Uber's programme of planetary expansion. Uber, like other platforms, privileges growth at all costs in order to spin up a set of self-reinforcing dynamics like virtuous cycles and network effects. However, Uber can also be reframed as a contemporary incarnation of empire. Platforms extend their territories in a programme of aggressive expansion rationalised by future financial gains. The second half of the article sought to combine these self-perpetuating technical dynamics with the self-expanding logics of empires. Against the assumed brilliance of founders and start-up strategy, this framing explored some of the uncontrolled forces and overarching imperatives that both invest and constrain platforms. 
Such an emphasis contributes to platform studies by offering a frame of critique concerned with the broader political economies of platforms and the critical underlying operations that support them. Of course, this research is also necessarily limited. While this article has investigated Uber, future research might conduct a comparison between Uber and similar platforms such as Airbnb, earlier incarnations like Google and Facebook, or non-Western counterparts such as WeChat and Baidu. Another research avenue would be to update this analysis by investigating Uber's expansion over the last year, particularly in light of increased regulation and competition within the platform space. Such investigations would aim to identify a set of broader platform logics, whether propelled by network dynamics or compelled by imperialist expansion. Spun up by platforms, such drives develop their own inertia, incorporating spaces and instrumentalising labour based on their own imperatives.

\section{References}

Amarsy, Nabila. 2015. "Switching Costs: 6 Ways To Lock Customers Into Your Ecosystem." Strategyzer. July 27, 2015. Accessed July 9, 2019. https://blog.strategyzer.com/posts/2015/7/27/switching-costs-6-strategies-to-lock-customers-in-your-ecosystem

Anazodo, Tikue. 2016. How 'Aggregation Theory' Is Fueling a Multi-Trillion Dollar Technology Revolution. Medium, February 3. Accessed June 24, 2019. https://medium.com/adventures-in-consumer-technology/how-aggregation-theory-is-fueling-a-multi-trillion-dollartechnology-revolution-ce5ab03ca4bc

Anwar, Syed Tariq. 2018. Growing Global in the Sharing Economy: Lessons from Uber and Airbnb. Global Business and Organizational Excellence 37 (6): 59-68. https://doi.org/10.1002/joe.21890

Arendt, Hannah. 1976. Imperialism. Vol. 2. The Origins of Totalitarianism. New York: Houghton Mifflin Harcourt.

Arrighi, Giovanni. 2010. The Long Twentieth Century: Money, Power and the Origins of Our Times. London: Verso.

Arrighi, Giovanni. 1978. The Geometry of Imperialism: The Limits of Hobson's Paradigm. London: New Left Books.

Barabási, Albert-László. 2002. Linked: The New Science of Networks. Cambridge, MA: Perseus Publishing.

Berls, Bruce. 2018. All Your Loyalties Are Belong To Us: How Technology Companies Lure Us Into Walled Gardens. Bruceb News [blog], August 13. Accessed May 23, 2019. https://www.brucebnews.com/2018/08/all-your-loyalties-are-belong-to-us-how-technologycompanies-lure-us-into-walled-gardens/

Bogage, Jacob. 2016. Uber's Controversial Strategy to Finally Defeat Lyft. Washington Post, August 23. Accessed February 19, 2018. https://www.washingtonpost.com/news/theswitch/wp/2016/08/23/ubers-controversial-strategy-to-finally-defeat-lyft/

Bond, Andrew T. 2015. An App for That: Local Governments and the Rise of the Sharing Economy. Notre Dame Law Review Online 90: 77-96.

Casadesus-Masanell, Ramon, and Joan E. Ricart. 2011. How to Design a Winning Business Model. Harvard Business Review 89 (1/2): 100-107.

Choudary, Sangeet Paul. 2015. Platform Scale: How an Emerging Business Model Helps Startups Build Large Empires with Minimum Investment. n.p: Platform Thinking Labs.

Coase, R. H. 1937. The Nature of the Firm. Economica 4 (16): 386-405. https://doi.org/10.1111/j.1468-0335.1937.tb00002.x

Codagnone, Cristiano, Jacob Matthews, and Athina Karatzogianni. 2018. Platform Economics: Digital Labour Organization in the Sharing Economy. Bingley, Bradford: Emerald Publishing Limited. 
Dudley, Geoffrey, David Banister, and Tim Schwanen. 2017. The Rise of Uber and Regulating the Disruptive Innovator. The Political Quarterly 88 (3): 492-99.

https://doi.org/10.1111/1467-923X.12373

Fiegerman, Seth. 2017. Uber Is Losing Billions: Here's Why Investors Don't Care. CNNMoney, June 1. Accessed November 29, 2017. http://money.cnn.com/2017/06/01/technology/business/uber-losses-investors/index.html

Fink, Erica. 2014. Uber's Dirty Tricks Quantified: Rival Counts 5,560 Canceled Rides. CNNMoney, August 11. Accessed November 30, 2017. http://money.cnn.com/2014/08/11/technology/uber-fake-ride-requests-lyft/index.html

Fowler, Susan. 2017a. Reflecting on One Very, Very Strange Year at Uber. Susan Fowler [blog], February 19. Accessed November 30, 2017. https://www.susanjfowler.com/blog/2017/2/19/reflecting-on-one-very-strange-year-at-uber

Fowler, Susan. 2017b. It's All a Show. It's All Optics. Whatever It Takes to Win Back the Riders from the Competition, Right? Tweet. @susanthesquark [blog], June 7. Accessed November 30, 2017. https://twitter.com/susanthesquark/status/875946810086268929?lang=en

Fuchs, Christian. 2016. Digital Labor and Imperialism. Monthly Review 67 (8): 14-24.

Gannes, Liz. 2014. Travis Kalanick: Uber Is Raising More Money to Fight Lyft and the 'Asshole' Taxi Industry. Recode, May 28. Accessed May 14, 2018. https://www.recode.net/2014/5/28/11627354/travis-kalanick-uber-is-raising-more-money-to-fight-lyft-and$\underline{\text { the }}$

Geron, Tomio. 2013. Airbnb And The Unstoppable Rise Of The Share Economy. Forbes, February 11. Accessed June 24, 2019. https://www.forbes.com/sites/tomiogeron/2013/01/23/airbnb-and-the-unstoppable-rise-of-the-share-economy/

Gibbs, Samuel. 2017. Leaked Uber Sex Memo Throws New Spotlight on Frat-House Culture. The Guardian, June 9. Accessed November 30, 2017. http://www.theguardian.com/technology/2017/jun/09/leaked-uber-sex-memo-frat-house-culture-sexism-ceo-travis-kalanick

Gillespie, Tarleton. 2010. The Politics of 'Platforms.' New Media \& Society 12 (3): 347-64. https://doi.org/10.1177/1461444809342738

Griffin, Tren. 2017. Business Lessons from Ben Thompson of Stratechery. 25iq, November 18. Accessed June 24, 2019. https://25iq.com/2017/11/18/business-lessons-from-benthompsons-stratechery/

Grossman, Sanford J., and Oliver D. Hart. 1986. The Costs and Benefits of Ownership: A Theory of Vertical and Lateral Integration. Journal of Political Economy 94 (4): 691-719. https://doi.org/10.1086/261404

Harris, Derrick. 2012. The One-Night Stand, Quantified and Visualized by Uber. March 26. Accessed November 30, 2017. https://gigaom.com/2012/03/26/uber-one-night-stands/

Helmond, Anne. 2015. The Platformization of the Web: Making Web Data Platform Ready. Social Media + Society 1 (2): n.p. https://doi.org/10.1177/2056305115603080

Hill, Kashmir. 2014. 'God View': Uber Allegedly Stalked Users For Party-Goers' Viewing Pleasure (Updated). Forbes, October 3. Accessed November 30, 2017. https://www.forbes.com/sites/kashmirhill/2014/10/03/god-view-uber-allegedly-stalked-users-for-party-goers-viewing-pleasure/

Hobson, John Atkinson. 1902. Imperialism: A Study. New York: James Pott \& Company. Isaac, Mike. 2017. How Uber Deceives the Authorities Worldwide. The New York Times, March 3. Accessed November 30, 2017. https://www.nytimes.com/2017/03/03/technology/uber-greyball-program-evade-authorities.html

Jin, Dal Yong. 2017. Digital Platforms, Imperialism and Political Culture. New York: Routledge.

Jones, Rhett. 2017. Report: Uber CEO's Group Trip To Escort Bar Made Female Employee 'Feel Horrible.' Gizmodo Australia, March 26. Accessed November 30, 2017. https://www.gizmodo.com.au/2017/03/report-uber-ceos-group-trip-to-escort-bar-made-female-employee-feel-horrible/ 
Jünger, Friedrich Georg. 1990. The Failure of Technology. Washington, D.C.: Regnery Gateway.

Kaminska, Izabella. 2016. The Taxi Unicorn's New Clothes. FT Alphaville, December 2. Accessed February 19, 2018. https://webcache.googleusercon-

tent.com/search?q=cache:Gh1bBHDFqiMJ:https://ftalphaville.ft.com/2016/12/01/2180647/the-taxi-unicorns-newclothes $/+\& c d=1 \& h l=$ en $\& \mathrm{ct}=\mathrm{clnk} \& \mathrm{gl}=\mathrm{nz}$

Khosrowshahi, Dara. 2017. Uber's New Cultural Norms. Linkedin, November 7. Accessed November 29, 2017. https://www.linkedin.com/pulse/ubers-new-cultural-norms-darakhosrowshahi

Langlois, Richard. 2006. The Secret Life of Mundane Transaction Costs. Organization Studies 27 (9): 1389-1410.

Lynley, Matthew. 2016. Travis Kalanick Says Uber Has 40 Million Monthly Active Riders. TechCrunch [blog], October 19. Accessed November 29, 2017. http://social.techcrunch.com/2016/10/19/travis-kalanick-says-uber-has-40-million-monthly-activeriders/

Madhavan, Abhishek. 2017. Why Distribution Still Matters in the Internet Age. WIRED, April 6. Accessed November 29, 2017. https://www.wired.com/2017/04/why-distribution-stillmatters-in-the-internet-age/

Marx, Karl. 2004/1867. Capital: A Critique of Political Economy. Translated by Ben Fowkes. London: Penguin Books.

Matulis, Brett S. 2016. The Coercive Laws of Competition in a Neoliberal Era: The Case of Forestry in Costa Rica. UAiR Journal of Political Ecology 23 (1): 279-95.

Metcalfe, Bob. 2013. Metcalfe's Law after 40 Years of Ethernet. Computer 46 (12): 26-31.

Metcalfe, Robert M. 2007. It's All In Your Head. Forbes, April 20. Accessed June 27, 2019. https://www.forbes.com/forbes/2007/0507/052.html

Milian, Mark. 2014. Uber's International 'Launch Playbook' Includes Some Tough Lessons. Bloomberg.Com, November 20. Accessed November 29, 2017. https://www.bloomberg.com/news/articles/2014-11-20/ubers-international-launch-playbook-includes-sometough-lessons

Moed, Jonathan. 2018. Uber's Wild Ride To Make Latin America Its Fastest Growing Region. Forbes, December 20. Accessed June 24, 2019. https://www.forbes.com/sites/jonathanmoed/2018/12/20/is-uber-operating-illegally-in-its-fastest-growing-region/

Munn, Luke. 2018. Ferocious Logics: Unmaking the Algorithm. Lüneburg: meson press.

Muzellec, Laurent, Sébastien Ronteau and Mary Lambkin. 2015. Two-Sided Internet Platforms: A Business Model Lifecycle Perspective. Industrial Marketing Management 45 (February): 139-50. https://doi.org/10.1016/j.indmarman.2015.02.012

Newcomer, Eric. 2017. Uber, Lifting Financial Veil, Says Sales Growth Outpaces Losses. Bloomberg.Com, April 14. Accessed November 29, 2017. https://www.bloomberg.com/news/articles/2017-04-14/embattled-uber-reports-strong-sales-growth-aslosses-continue

Newton, Casey. 2014. This Is Uber's Playbook for Sabotaging Lyft. The Verge, August 26. Accessed November 29, 2017. https://www.theverge.com/2014/8/26/6067663/this-is-ubers-playbook-for-sabotaging-lyft

Nunez, Michael. 2016. Why Uber Is Losing Money Faster Than Any Tech Company Ever. Gizmodo Australia, August 26. Accessed February 19, 2018. https://www.gizmodo.com.au/2016/08/why-uber-is-losing-money-faster-than-any-tech-company-ever/

OMR Festival. 2016. "The Go-To for Those in the Know - Ben Thompson". November 18. Accessed June 24, 2019. https://omr.com/en/ben-thompson-stratechery-omr-festival-live/

Prosperity Analytics. 2014. St. Patrick's Day, Uber, and LTV. Prosperity Analytics [blog], March 28. Accessed November 29, 2017. https://prosperityanalytics.wordpress.com/2014/03/28/st-patricks-day-uber-and-ltv/ 
RideGuru. 2016. What Is Uber's Safe Rides Fee? December 11. Accessed November 29, 2017. https://ride.guru/lounge/p/what-is-ubers-safe-rides-fee-what-is-the-big-fuss-about

Rochet, Jean-Charles, and Jean Tirole. 2003. Platform Competition in Two-Sided Markets. Journal of the European Economic Association 1 (4): 990-1029. https://doi.org/10.1162/154247603322493212

Rothman, Simon. 2016. Why Uber Won. Business Insider, April 20. Accessed November 29, 2017. http://www.businessinsider.com/why-uber-won-2016-4

Ryan, Kevin J. 2017. Uber Wants to Make the Suburbs as Connected as Cities. Here's Why Lyft Might Get There First. Inc.Com, February 27. Accessed June 24, 2019. https://www.inc.com/kevin-j-ryan/lyft-uber-future-of-on-demand-rides.html

Schwarz, Jonas Andersson. 2017. Platform Logic: An Interdisciplinary Approach to the Platform-Based Economy. Policy \& Internet 9 (4): 374-94. https://doi.org/10.1002/poi3.159

Slee, Tom. 2017. What's Yours Is Mine: Against the Sharing Economy. New York: OR Books.

Smith, Ben. 2014. Uber Executive Suggests Digging Up Dirt On Journalists. BuzzFeed, November 17. Accessed November 30, 2017. https://www.buzzfeed.com/bensmith/uber-executive-suggests-digging-up-dirt-on-journalists

Solon, Olivia. 2017. How Uber Conquers a City in Seven Steps. The Guardian, April 12. Accessed November 29, 2017. http://www.theguardian.com/technology/2017/apr/12/whyeveryone-hates-uber-seven-step-playbook

Somerville, Heather, and Joseph Menn. 2017. Uber CEO Takes Leave of Absence amid Sweeping Changes after Scandals. Reuters, June 14. Accessed November 29, 2017. https://www.reuters.com/article/us-uber-board/uber-ceo-kalanick-to-take-leave-of-absence-idUSKBN1942EG

Srnicek, Nick. 2017. Platform Capitalism. Cambridge: Polity Press.

Sundararajan, Arun. 2016. The Sharing Economy: The End of Employment and the Rise of Crowd-Based Capitalism. Cambridge, MA: MIT Press.

Thompson, Ben. 2017. The Super-Aggregators and the Russians. Stratechery, September 18. Accessed November 29, 2017. https://stratechery.com/2017/the-super-aggregatorsand-the-russians/

Thompson, Ben. 2015. Aggregation Theory. Stratechery, July 21. Accessed November 29, 2017. https://stratechery.com/2015/aggregation-theory/

Thompson, Ben. 2014. Why Uber Fights. Stratechery, November 24. Accessed November 29, 2017. https://stratechery.com/2014/uber-fights/

Tucker, Eric. 2018. Uber and the Unmaking and Remaking of Taxi Capitalisms: Technology, Law and Resistance in Historical Perspective. In Law and the "Sharing Economy": Regulating Online Market Platforms, edited by Derek McKee, Finn Makela, and Teresa Scassa, 357-92. Ottawa: University of Ottawa Press.

Uber Technologies Inc. 2019. Form S-1. Registration Statement. Washington, D.C.: Securities and Exchange Commission. https://www.sec.gov/Archives/edgar/data/1543151/000119312519103850/d647752ds1.htm

Warzel, Charlie. 2014. Sexist French Uber Promotion Pairs Riders With 'Hot Chick' Drivers. BuzzFeed, October 22. Accessed November 30, 2017. https://www.buzzfeed.com/charliewarzel/french-uber-bird-hunting-promotion-pairs-lyon-riders-with-a

Watanabe, Chihiro, Kashif Naveed, Pekka Neittaanmäki, and Brenda Fox. 2017. Consolidated Challenge to Social Demand for Resilient Platforms - Lessons from Uber's Global Expansion. Technology in Society 48 (February): 33-53. https://doi.org/10.1016/j.techsoc.2016.10.006

Wong, Julia Carrie. 2017. Uber CEO Travis Kalanick Resigns Following Months of Chaos. The Guardian, June 21. Accessed November 29, 2017. http://www.theguardian.com/technology/2017/jun/20/uber-ceo-travis-kalanick-resigns

Zhang, Xing-Zhou, Jing-Jie Liu, and Zhi-Wei Xu. 2015. Tencent and Facebook Data Validate Metcalfe's Law. Journal of Computer Science and Technology 30 (2): 246-51. 


\section{About the Author}

\section{Luke Munn}

Based in Tāmaki Makaurau, Aotearoa New Zealand, Luke Munn uses both practice-based and theoretical approaches to explore the intersections of digital cultures, investigating how technical environments shape the political and social capacities of the everyday. He is currently completing a PhD at Western Sydney University on algorithmic power. 